\title{
FILOSOFIA COM CRIANÇAS NA ESCOLA: PRÁTICAS DE LEITURA, ESCRITA E EXERCÍCIO DO PENSAMENTO NA PROBLEMATIZAÇÃO DO TEMPO
}

\author{
S. LERMEN", B. SCHULER \\ Universidade do Vale do Rio dos Sinos \\ binalermen@gmail.com ${ }^{*}$
}

Submetido 04/07/2017 - Aceito 28/02/2018

DOI: $10.15628 /$ holos. 2018.6090

\begin{abstract}
RESUMO
Este artigo investiga o exercício do pensamento, pautado pela prática da filosofia com crianças (diferenciando-se da filosofia para crianças), através de práticas de leitura e escrita em uma escola pública na região do Vale do Caí, RS. A partir da perspectiva do pensamento da diferença, operando com autores como Foucault, Deleuze e Kohan, interroga-se de que modos essa experimentação poderia produzir pequenos deslocamentos quanto aos clichês e pensamentos dogmáticos que atravessam nossas vidas. Essa investigação entende 0 pensamento como essa provocação do fora, viabilizado por diferentes intercessores que irão problematizar o que está naturalizado. Do mesmo modo, opera com a filosofia para além de uma disciplina acadêmica, como uma forma específica de se relacionar com o saber e com a vida. Entende, ainda, a escrita como uma técnica que
\end{abstract}

pode operar transformações sobre nossa experiência. A partir disso, realizou-se a análise de escritas de alunos de 5을 ano, cujas regularidades destacadas foram: o discurso salvacionista, valoração da escola como lugar de pensamento, a boa escrita operada como comunicação e a expressão de grande preocupação com a passagem do tempo. A partir dessas regularidades, produziu-se uma oficina filosófica com esses alunos, em que foram inventadas outras possibilidades de leitura e escrita, focando na problematização de nossas relações com o tempo. As escritas produzidas nessa oficina foram igualmente examinadas, destacando-se, pois, uma divisão temporal (e moral) da vida, mas também apresentando deslocamentos importantes quanto ao tempo cronológico, operando com uma diminuição da força pastoral e da infância idealizada, apostando em uma relação mais intensiva com o mesmo.

PALAVRAS-CHAVE: filosofia com crianças, exercício do pensamento, escrita, leitura, tempo.

\section{PHILOSOPHY WITH CHILDREN AT SCHOOL: PRACTICES OF READING, WRITING AND EXERCISE OF THOUGHT TO PROBLEMATIZE TIME}

\begin{abstract}
This article investigates the exercise of thought trough the practice of philosophy with children (differently of philosophy to children) by means practices of writing and reading in a public school in Brazil. Based on a thought of difference perspective, operating with authors such as Foucault, Deleuze and Kohan, it interrogates the modes that this experimentation could produce little dislocations about clichés and dogmatic thoughts that intertwine our lives. This research understands thought as this provocation from outside, made possible by different intercessors that will problematize what is taken as natural. In the same way, this article operates with philosophy beyond an academic discipline, but as a specific way to deal with knowledge and life. Also, writing is taken as a technique that can transforms our experience. Based on theseconcepts, the student primary school writings
\end{abstract}

were examined and some regularities were diagnosed: the salvation discourse, the evaluation of school as the place of thought, the good writing understood as communication, and the expression of preoccupation with the passing of time. From these regularities, it was produced a philosophic workshop with these primary school students, in which were created other ways do deal with writing and reading, focusing in the problematization of our relations with time. Writings produced in these workshops were also examined and it is possible to highlight the temporal division (and moral) of time, but also is possible to see some important dislocations about chronologic time, operating with a decrease of pastoral power and the idealized childhood, investing in a more intensive relation with time.

KEYWORDS: philosophy with children, exercise of thought, writing, reading, time. 


\section{UM COMEÇO}

Este artigo se propõe a investigar escritas escolares produzidas por alunos de quintos anos de uma escola pública na região do Vale do Caí, RS, buscando entender como estava sendo operado o exercício do pensamento. A partir disso, buscou-se potencializar esses exercícios de pensamento pautados pelo trabalho de filosofia com crianças em práticas de escrita e leitura na escola.

Embasadas por autores tais como Foucault, Deleuze e Kohan e por investigações em escolas nas quais a escrita e a leitura são reduzidas a sua função comunicativa, nos colocamos a problematizar: de que modos o trabalho de filosofia com crianças na escola poderia potencializar o pensamento a partir de práticas de leitura e escrita? Esses autores fornecem ferramentas conceituais para investigarmos de que modos esse exercício do pensamento é operado através de práticas de leitura e escrita, optando aqui por trabalhar com os conceitos: filosofia com crianças, leitura, escrita e exercício do pensamento.

Desse modo, diagnosticamos alguns funcionamentos nessas escritas, como o discurso salvacionista, a escola valorada como local de pensamento, a boa escrita entendida como comunicação e a grande preocupação que as crianças traziam com a passagem do tempo. A partir disso, como outra dobra metodológica, elaborou-se oficinas filosóficas com essas crianças, focando na problematização de nossas relações com o tempo na contemporaneidade. Com essa experimentação, pode-se destacar um deslocamento quanto à relação apenas cronológica com o tempo, apostando-se em uma diminuição da força pastoral nos textos, bem como da lidação idealizada com a infância.

\section{DA RELAÇÃO ENTRE FILOSOFIA, INFÂNCIA E PENSAMENTO}

O trabalho de filosofia com crianças surge com uma provocação do professor Matthew Lipman já na década de 1960. Instigado pela hipótese de que o desenvolvimento do raciocínio chegava tarde, foi voltando-se à caminhada escolar dos alunos até a chegada à universidade, se perguntando se seria possível ajudar os alunos quando crianças a "pensarem bem". Assim, criou o programa Filosofia para crianças, na tentativa de que o contato com a filosofia desde cedo fosse capaz de ampliar o modo de pensar, raciocinar e articular os saberes das crianças, tornando-as boas pensadoras. Lipman "não apenas lançou uma ideia, mas criou uma instituição e desenvolveu materiais e metodologia para que esta ideia fosse uma realidade" (KOHAN; WUENSCH, 1998, p. 9). Programa esse que adentrou escolas públicas de vários países - rompendo com a elitização dos saberes escolares e democratizando seu acesso - e adotado, também, por escolas privadas.

Seguindo uma linha de pensamento específica - neste caso o de comunidade de questionamento e investigação - e com material e metodologia próprios, muitos críticos afirmaram que o programa limita a liberdade de pensamento dos participantes. A comunidade de questionamento e investigação/indagação consiste no questionamento das crenças e verdades, através do pensamento rigoroso e discussão democrática, constituindo "uma espécie de comunidade científico-filosófica em miniatura que procura fazer com que as crianças se tornem 
mais dialógicas e razoáveis" (LÓPEZ, 2008, p. 14). Assim, a comunidade, indefinida e sem limites, vai definindo o que se compreende como verdade.

Entretanto, diferentemente do proposto por Lipman, que centrou seus esforços no trabalho de filosofia para crianças, esta pesquisa trabalhará com a ideia de filosofia com crianças, proposto por Kohan (1999), ampliando as possibilidades dessa mudança sintática. Todavia, antes de adentrar tal discussão, entendemos que se faz importante marcar algumas relações entre a filosofia e as infâncias.

Anteriormente ao discurso moderno de infância, as crianças eram atravessadas pelo pensamento filosófico. Não na perspectiva da filosofia com crianças, mas havia uma preocupação do quanto a filosofia poderia influenciar no tipo de educação que recebiam. Pode-se citar, por exemplo, a discussão socrática-platônica que afirmava que o ato de filosofar estava fortemente vinculado à política e ao governo. Por isso, necessitava-se ter cuidado com os textos usados para educar as crianças, não deixando que conhecessem certos assuntos, afinal, a extirpação da injustiça na pólis dependeria da boa educação das crianças (KOHAN, 2003). Para os gregos, a criança quando crescia e se tornava adulta, deveria preocupar-se com questões da pólis, daí o cunho político da educação das crianças; ressaltando que aqui se tratavam de algumas crianças, pois poucas tinham acesso a esse tipo de educação.

O conceito de infância, todavia, é muito recente, datando do século XVI. A tese de Ariès (1981) apresenta uma visão de criança, na época medieval, como um adulto em miniatura, uma fase muito curta da vida e trazia a passagem da fase infantil para a adulta através do conhecimento e uso da linguagem. A partir dos século XVII e XVIII, "a criança passa a ser o centro das atenções dentro da instituição familiar" (KOHAN, 2003, p. 66), iniciando o processo de planejamento de práticas e lugares específicos para esse período da vida, constituindo-se uma ideia romantizada sobre a infância.

Segundo Matos (2009, p. 1) podemos pensar que a ideia da criança está relacionada aos "aspectos cognitivo, social, físico, biológico, neurológico, psicomotor e psicológico" e infância, pluralizada - infâncias -, estabelece a diversidade de concepções aceitas e que se relacionam, constituindo a nossa compreensão atual desse conceito. Dessa forma, a autora afirma que as crianças são atravessadas de infâncias. E essas crianças precisam ser ensinadas, daí a forte vinculação entre a invenção da infância, a constituição da escola moderna e os processos de disciplinamento. Kohan (2003, p. 80-81), inspirado em Foucault, afirma quanto a condução das condutas na escola que:

O que percebemos, dizemos, julgamos, pensamos e fazemos numa escola está imerso num complexo jogo de práticas discursivas e não-discursivas que geram as condições para que tenhamos uma certa experiência de nós mesmos; em outras palavras, para que sejamos aquilo que estamos sendo.

Dessa forma, o que compreendemos hoje por tudo o que compõe o universo infantil faz parte de uma produção histórica, consolidada a partir do século XVII. Nesse processo, essa infância 
idealizada, romantizada e cada vez mais disciplinarizada, vai sendo produzida nesses discursos pedagógicos, mas também médicos, religiosos, que a marcam pela dimensão de falta.

A educação passa a ser um imperativo [...], constituindo-se de discursos voltados para o estudo e a acumulação de saberes sobre a criança e seu corpo, seu desenvolvimento, suas capacidades, suas vontades, suas tendências, suas brincadeiras, suas potencialidades, suas fragilidades, suas vulnerabilidades, seus instintos, suas paixões e potências que, por sua vez, se acoplam a práticas discursivas e não discursivas em que tais saberes se imbricam em mecanismos de poder, cujo resultado será a produção de uma criança específica, a produção da subjetividade infantil moderna (RESENDE, 2015, p. 129-130).

Deslocando-nos dessa perspectiva, podemos pensar a infância em suas potências. Kohan (2003, p. 63), inspirado por Foucault, vê "a infância como sentimento e como saber e poder, no jogo de relações entre o pensamento e a verdade", problematizando as diversas concepções que constituem as infâncias na contemporaneidade. Assim, "pensar com Foucault faz ver o que se está fazendo da infância e com a infância em nosso tempo presente" (RESENDE, 2015, p. 137).

A partir dessas condições, o campo da filosofia da educação produz certas problematizações quanto a essa escola que busca conservar a cultura e, ao mesmo tempo, produzir outras criações (LÓPEZ, 2008), daí a potência do trabalho da filosofia com crianças. Todavia, as Diretrizes Curriculares Nacionais para a Educação Básica em vigência traz como exigência curricular o ensino de Filosofia somente para o Ensino Médio, isto aprovado apenas em 2008, na Lei no 11.684, o que significa que anteriormente essa área não era obrigatória ${ }^{1}$. A ressalva está na sua ausência para os anos anteriores da educação básica (apesar de algumas poucas redes de ensino atuarem com a filosofia nos anos finais do Ensino Fundamental).

Todavia, quando se fala em filosofia com crianças, não se está a reduzindo a uma disciplina curricular, mas a um modo de trabalhar com o pensamento e a existência. A filosofia, concebida anteriormente ao conceito de infância, também vinculada à Grécia antiga, era entendida por Sócrates, por exemplo, como um caminho de interrogação, concepção essa que ainda atravessa nosso entendimento contemporâneo. Kohan (2009, p. 21) afirma que "o que Sócrates empreende é uma busca de sentido, e o modo de realiza-la é a interrogação de si e dos outros" e complementa dizendo que "é a própria busca que dá forma a uma prática que faz de Sócrates [...] algo que ele não era no início.". Nesse contexto socrático, a filosofia é compreendida como um modo de relação com o saber, que transforma o que somos e o que pensamos, que problematiza os valores usualmente valorados. Então, "viver filosofando significa, para Sócrates, dar um lugar de destaque, no pensamento e na vida, à ignorância, ter uma relação de potência, afirmativa, generativa, com a ignorância.". (KOHAN, 2009, p. 25).

\footnotetext{
${ }^{1}$ A obrigatoriedade da filosofia para o Ensino Médio foi posta em cheque na primeira versão da Reforma do Ensino Médio em 2016. Na atual versão (terceira) da Base Nacional Comum Curricular (BNCC) que se encontra sob avaliação no Conselho Nacional de Educação (CNE) não aparece a disciplina de Filosofia para o Ensino Fundamental, sendo discutida nas Artes, dentro de uma das dimensões dessa linguagem (chamada de crítica), como uma possibilidade de articulação de pensamentos propositivos.
} 
Segundo essa concepção, a filosofia tem como objeto o próprio pensamento, a relação consigo e com os demais. Assim, fazer filosofia não é apenas refletir sobre determinado assunto, porque nem tudo que se faz constitui-se em prática filosófica, principalmente na escola e com as crianças. Mas, "o que está em jogo ao ensinar e aprender filosofia não é se sabemos ou não sabemos distinguir uma falácia de outra [...], é se de verdade ela chega a afetar o modo de vida daqueles que a compartilham" (KOHAN, 2009, p. 38).

Entendemos que existem inúmeras outras definições do conceito de filosofia, mas aqui optamos por operar como esse exercício do pensamento sobre o próprio pensamento, problematizando nossas verdades e modos de existência. Poderíamos, igualmente, tomar Sócrates por várias questões, mas decidimos eleger a figura de filósofo que exerceu em sua vida. Foucault (2005, p. 35), inspirado em Nietzsche, conceitua o filósofo como "aquele que podia diagnosticar o estado do pensamento". Desse modo, Gallo e Veiga-Neto $(2007$, p. 6) afirmam que, "para além de ser um dos pilares, um dos fundamentos da educação, a filosofia precisa ser para a educação justamente aquilo que lhe tira os fundamentos, aquilo que lhe tira o chão, fazendo com que o pensamento uma vez mais emirja".

A partir dessa perspectiva, a filosofia é uma postura, indo muito além de uma área de conhecimento. Por isso, seu trabalho é constante, inacabado e busca compreender como a verdade foi sendo estabelecida como um valor, ou seja, busca saber a história da verdade, como se constituiu nesse valor e como é capaz de produzir exercícios de poder (FOUCAULT, 2005). A filosofia entendida por esse pensamento da diferença, assim, não busca respostas, mas coloca perguntas e problematiza o pensamento a partir delas, os modos de subjetivação e como se constituem dentro de um contexto histórico, como nos leva a nos conduzirmos de determinadas formas. Nesse sentido, Foucault (2007, p. 13) indaga: “[...] mas o que é o filosofar [...], a atividade filosófica - senão o trabalho crítico do pensamento sobre o próprio pensamento? Se não consistir em tentar saber de que maneira e até onde seria possível pensar diferentemente em vez de legitimar o que já se sabe"?

Inspirado em Deleuze, Kohan (2003, p. 209) diz que o trabalho filosófico é um trabalho de solidão, mas atravessado pelo encontro com pessoas, conceitos, textos, acontecimentos, uma vez que "pensar é encontrar, [...] é o acontecimento do encontro que se passa entre duas ideias, conceitos, acontecimentos". Então, no exercício do pensamento é que acontece o trabalho filosófico, entendido como aquele que nos faz pensar diferentemente do que pensamos e nos deslocarmos minimamente de nós mesmos (FOUCAULT, 2007). Exercício sugere prática. Portanto, podemos tomar a prática filosófica criando possibilidades para o exercício do pensamento. Distingue-se, assim, da mera reflexão, buscando as relações com a verdade, ocupando-nos com as perguntas em detrimento das respostas e exercendo o pensamento diferencial, o qual seria um pensar sem subjetividades fixadas, operando com outras linguagens para além da perspectiva da representação. Pode-se tomar, pois, que o fazer filosofia, nessa perspectiva, passa para além da contemplação, por uma prática. Kohan (2003) traz, a partir de Deleuze, que o pensar produz intervenções nos modos de pensar do seu tempo.

E quando deslocamos da relação com as infâncias como sendo da ordem da falta e nos relacionamos com sua potência de criação, abrimos espaço com as crianças para outros modos de pensar o pensamento. Assim, o pensar não está dado no pensamento, precisa ser provocado pelo 
fora; é sempre ação e fluxo. Portanto, pensar é diferente de conhecer. López (2008, p. 55), a partir dos estudos de Deleuze, evidencia que "só pensamos quando somos provocados desde fora de nosso poder, de nosso saber". Nessa perspectiva, o pensamento diferencial distingue-se do pensamento dogmático, que acontece por representação e não problematiza o próprio pensamento, operando por manutenção. O pensar, ao contrário, exige encontro, acontecimento, movimento. Por isso que o exercício de pensar não acontece naturalmente na atividade filosófica institucionalizada em que se desenvolvem modos de pensar dogmáticos e prescritivos.

Esse modo de operar com o pensar - pela inquietude constante e infinita - pode nos remeter às crianças, constituindo o trabalho desenvolvido pela filosofia com crianças (diferentemente da concebida por Lipman). Amplia-se, assim, as possibilidades desse fazer filosófico com as crianças em um exercício de criação de outras perguntas, perguntas produzidas como atos de pensamento, para além das perguntas da filosofia clássica e para além das perguntas operadas como obstáculo ao saber.

Desse modo, Kohan (1999, p. 60) conceitua o fazer filosófico através de duas dimensões, a crítica e a criativa: "como tarefa crítica, a filosofia questiona os valores, ideias, e crenças que permeiam as práticas socialmente dominantes. Ao mesmo tempo, como tarefa criativa, ela pensa as condições de possibilidade de outras ordens, alternativas às vigentes". Assim, com foco nessa pesquisa, a primeira dimensão - crítica - problematiza o mais natural e evidente em relação à infância e a segunda dimensão - criativa - buscaria pensar em que condições são afirmados esses valores naturalizados e, consequentemente, produzindo novos modos de pensar a infância e as relações consigo e com os demais.

Aprofundando essa concepção, Kohan (1999, p. 71) defende a prática de filosofia com crianças, em que a mesma não é um manual a ser aplicado, mas uma exercitação que "se pratica, se vive, se tem um experiência dela", deixando aberta a possibilidade de que o trabalho filosófico com crianças possa dar espaço para se originarem "filosofias das crianças", constituindo uma forma de produzir a diferença. Assim,

[...] a filosofia é este exercício ou experiência de pensamento em que a forma e o conteúdo se confundem na busca de pensar sempre de outra maneira, de não consagrar ou legitimar o que já se pensa e se sabe, mas de buscar sempre outras formas de pensar e saber (KOHAN, 2012, p. 39).

Essa prática filosófica pautada por problemas opera com os mesmos não como uma barreira a ser superada, mas como a possibilidade mesma do pensamento de se chegar no limite do abismo, dessa relação com o fora, com esse fundo trágico que permite ainda a criação de outros sentidos além dos clichês. Desse modo entendida, a prática filosófica com crianças poderia produzir irrupções no próprio pensamento e abrir possibilidades para além dos pressupostos iniciais. Inspirado em Sócrates, Kohan (2009) afirma que o trabalho filosófico na escola pode ser desafiador, justamente por problematizar a institucionalização do ensino de filosofia, que acaba por limitar o pensamento e cessa seu exercício criador e potencializador. Enfatiza e questiona: “o desafio se dá em cada pensamento, em cada leitura, em cada escritura, em cada vez que se entra 
em uma sala de aula: a serviço de que forças propomos o jogo da filosofia? A tarefa de descolonizar o próprio pensamento é infinita" (KOHAN, 2009, p. 85).

Por isso, o trabalho de filosofia com crianças não seria pautado pela busca de soluções, mas de colocações de outros problemas, pois negligenciar este aspecto seria renunciar ao exercício do pensamento (LÓPEZ, 2008). Portanto, a filosofia com crianças, ao invés de ensinar a história da filosofia, busca um exercício "não-dogmatizante" de pensar com os outros, em que se faz da filosofia uma experiência (LÓPEZ, 2008). E pensar com os outros não significa pensar o mesmo.

\subsection{Da escrita e da leitura na prática filosófica com crianças}

A partir da discussão anterior, a escrita e a leitura podem ser tomadas como operadores da prática filosófica com crianças, ultrapassando a mera expressão e comunicação da linguagem. Para tanto, escrita e a leitura para funcionarem como ruptura e abertura de possibilidades precisam conotar certa recusa. Recusa de manter os modos de pensar "comodidatizados", principalmente na escola. Poderiam, assim, romper com a ideia de expressão do pensamento (somente), como registro do já pensado, para deslocar-se para funcionar como exercício, como certo labor sobre o próprio pensamento e sobre si mesmo (FOUCAULT, 2004).

Nessa perspectiva, a escrita e a leitura são vistas como ferramentas capazes de operar com a subjetivação e como provocação do pensamento. Trata-se, pois, de uma vontade antirreducionista à escrita e à leitura, em que operassem com experiência, como técnica que provoca o pensamento, que modifica o modo de vida. Baseado em Foucault, Aquino (2011, p. 644) afirma que "escrever consistiria, assim, numa experiência de transformação do que se pensa e, acima de tudo, do que se é" e complementa que, nesse sentido, a escrita operaria como "uma operação avessa, ademais, a qualquer apelo comunicativo ou normativo". Escrever-se-ia, pois, para mudar-se a si mesmo e não para reafirmar aquilo que já se pensa.

As autoras Olegário e Munhoz (2014) conceituam essa escrita como ensaística. Esta faria algumas brechas na escrita escolar, que normaliza e controla e em cujo lugar a palavra de ordem é, normalmente, a reprodução. Esse modo experimental do pensamento vai operar com uma escrita como linguagem que problematiza a si, aos outros, o mundo. Larrosa $(2004$, p. 31$)$ enfatiza que,

O ensaio pode ser tomado como uma linguagem da experiência, como uma linguagem que modula de um modo particular a relação entre experiência e pensamento, entre experiência e subjetividade, [...] e tentando pensar, em relação a isso, os limites e as possibilidades de minhas próprias opções de escrita.

Dessa forma, o ensaio da escrita e da leitura poderia compor a operacionalização da e para a potência de pensamento, por meio da problematização dos modos de existência no presente. Aqui não se opera de forma romântica, dialética ou salvacionista, mas em brechas, sempre 
microfísicas dentro da escola, que se constituiu e ainda funciona como instituição de confinamento. Conforme Schuler (2014, p. 72),

Trata-se, pois, de invenção de possibilidades de respiro a uma moral de rebanho que nos engole com o entupimento curricular, com a escrita como duplicação da leitura e do pensamento tratado como explicação, [...] uma escrita não das substâncias, mas das forças, do exercício do pensamento e sua potência.

A partir disso, a leitura e a escrita podem ser operadoras do exercício do pensamento, a partir de uma prática filosófica como encontro, como prática de subjetivação, como "invenção de frestas". Esse modo de conceber a escrita poderia produzir uma potência de pensamento, uma lacuna sempre aberta para a possibilidade do leitor operar com outros sentidos, tecendo uma rede de relações diferenciais com o pensamento. Então, essas práticas podem possibilitar a criação de outras escritas, leituras, literaturas que não a dos livros pregadores, moralizantes, "burocratas do pensamento" (LARROSA, 2004), mas como uma arte de operar com outras forças.

Todavia, nossa escrita, ainda na contemporaneidade, vem sendo operada como a expressão dos movimentos interiores da alma, algo como um registro confessional, como uma prova da verdade, no rastro de uma lógica pastoral que é apropriada pelas Ciências Humanas. Portanto, faz-se necessário atuar eticamente com a escrita e a leitura e exercitar-se a partir delas. Com essa virada, o ato de ler e escrever poderia tomar posição de cuidado de si, de um exercício de si e para si, de recolher-se em si e atingir a si mesmo (FOUCAULT, 2004).

Para tomar a escrita nessa perspectiva, "é preciso compreendê-la menos como um deciframento de si por si do que como uma abertura que se dá ao outro sobre si mesmo" (FOUCAULT, 2004, p. 157). Quando se opera com essas práticas não para se tornar um objeto para um conhecimento verdadeiro por meio da leitura e da escrita, mas para criar um ethos nesse processo, abre-se a possibilidade de uma relação mais ética consigo e com os demais (FOUCAULT, 2011). Por isso, "[...] não se trata da amarração de um sujeito em uma linguagem; trata-se da abertura de um espaço onde o sujeito que escreve não para de desaparecer" (FOUCAULT, 2004, p. 209).

A partir dessa discussão conceitual, destacamos alguns sintomas levantados a partir das escritas examinadas, bem como a realização de uma oficina filosófica para problematizá-los, assim como o exame das escritas produzidas pelos alunos em tal oficina. Não pretendemos aqui a aplicação de tais conceitos, mas apenas um ensaio que buscou descolonizar os modos de existência em se tratando do exercício do pensamento com crianças em uma escola pública, de modo sempre microfísico.

\section{ESCRITA, INFÂNCIA E A PROBLEMATIZAÇÃO DO TEMPO}

Em um primeiro momento, foram coletados exercícios de escrita realizados por duas turmas de alunos do 5o ano em uma escola da região do Vale do Caí, RS, no ano de 2016. A análise consistiu em delimitar como o exercício da escrita é efetivado na escola: se força o pensamento a 
pensar outras coisas (SCHULER, 2014), se é uma escrita ensaística (OLEGÁRIO; MUNHOZ, 2014), se é vista como uma linguagem da experiência, se traz possibilidades de transgressão (FOUCAULT, 2011); se é burocrata do pensamento (LARROSA, 2004). Ressaltamos que não se trata de denunciar a escola, mas apenas possibilitar outros modos de pensar as práticas de leitura e escrita. Focamos em como essas práticas discursivas produzem modos de pensar e de viver (AQUINO, 2011), e também nossa relação com a verdade.

A grande maioria dos exercícios propostos diziam respeito à: produção de texto narrativo; produção de texto narrativo com criação de outro final; produção de poesia sobre a cidade; respostas para perguntas retiradas de um poema; criação de acróstico temático com eixo central "volta às aulas"; criação de diálogo, em duplas, com os diferentes usos dos porquês; elaboração de roteiro para criação de uma rádio, em grupos, com produção de notícia e propaganda; registro de observação de um passeio na cidade.

Cada uma dessas propostas gerou os exercícios que foram analisados e estes, por sua vez, foram examinados em suas regularidades e efeitos. A análise se deu a partir de questionamentos como: quais temas aparecem? Que discussões são feitas? Como a vida é tomada? Como se pensa sobre isso? Qual a relação que mantém com a língua? O que é recorrente nesses exercícios? O que eles pedem de produção para as crianças? Que modos de relação com o pensamento operam?

A partir do exame desses materiais, destacamos as seguintes regularidades: discurso salvacionista; valoração da escola como lugar de pensamento; "boa escrita" como comunicação e relação/preocupação com o tempo. Para recorte deste artigo, problematizaremos como a relação com o tempo era operada e como pôde ser problematizada em oficinas filosóficas.

Em muitas das escritas examinadas ficou fortemente destacada a preocupação das crianças com a rápida passagem do tempo e com modos de torná-lo utilitário. Esse sintoma nos leva a perguntar: as crianças sempre se preocuparam com a passagem do tempo? Sempre se preocuparam dessa forma utilitarista?

Essas escritas, aqui tomadas como técnicas por meio dos quais esses alunos e alunas estão aprendendo uma determinada relação consigo mesmos, operam esse discurso da rapidez como virtude e do bom uso do tempo, como tempo investido em trabalho. Veiga-Neto (2000, s.p.) afirma que "para a maior economia do poder disciplinar é preciso que o tempo em que se dão as experiências individuais siga uma ordenação", ou seja, ordenar o tempo na escola coloca em funcionamento um tipo específico de poder imbricados nas práticas pedagógicas na forma disciplinar. Essa ordem temporal indica que o tempo é fragmentado conforme as atividades e, por isso, conota utilidade e otimização para o processo de disciplinamento do sujeito. Ainda afirma que tornar o tempo utilitário facilita "para que cada corpo seja mais fácil, pontual e economicamente atingido e perpassado pelo poder disciplinar" (VEIGA-NETO, 2000, s.p.).

A partir disso, Veiga-Neto (2000) fala sobre a "espacialização do tempo", ao argumentar que até mesmo os espaços escolares são marcados pela fragmentação do tempo. Em um dos acrósticos examinados dizia: "Voltou as aulas, 'aleluia'. Ter observação é importante. Aleluia acabou a aula. O tempo tá passando. Eu não vou conseguir. Se eu me dedicar chego longe. Nossa, a hora tá passando rápido. Hoje a aula vai ser legal. Lanche ora. Acabou o tempo". 
Desse modo, relaciona-se com a vida a partir de uma lógica disciplinar, que opera o tempo quadriculado, otimizado e de forma objetiva. E, ainda, trabalha com a criança a partir de uma dimensão de falta, como um tempo em que ainda não se é, mas com a promessa de "ser alguém no futuro", desde que torne seu tempo produtivo no presente. Essa escrita coloca um tipo de pensamento que se ocupa do tempo de modo utilitário e linear. A preocuparação com sua passagem é operada em várias escritas examinadas, dividindo-o em certa duração e importância nos diferentes momentos de suas vidas - principalmente na escola -, dentro da lógica utilitária/produtivista que conota o tempo como objeto a ser possuído. Assim,

As nossas ações não se dão simplesmente ao longo de uma duração de tempo; muito mais do que isso, é na própria ação que se institui um tempo capaz de ser percebido e de ter algum sentido para nós. Dito de outra maneira, o tempo se institui e se organiza pela nossa ação (VEIGA-NETO, 2000, s. p.).

Essa preocupação tão contemporânea que atravessa as infâncias no presente marcam um modo de relação com o pensamento e com a vida; falam de um sintoma do presente. Várias poderiam ser as escritas das crianças aqui citadas: "não posso perder mais um segundo", "o tempo tá passando" e "nossa, a hora tá passando rápido", além de escritas que dividem a vida cronologicamente, marcando o tempo de produção e trabalho como a parte mais importante da vida. Assim, essas escritas atravessam os modos de constituição infantis e suas relações com o mundo e consigo mesmos na sociedade ainda disciplinar, mas também de controle em que vivemos. Relação essa marcada por um tempo extensivo, da ordem da medida e da produtividade, que vai produzir a infância como esse lugar diminuído, de falta, porque ainda não vive o tempo do trabalho, mas que assume valor como promessa de futuro. A partir desses sintomas, questionamos:

Quais as condições para pensar e fazer outras perguntas que não sejam eminentemente parte do discurso metafísico da linguagem? [...] Em que condições de possibilidade são consideradas a leitura e a escrita na escola? [...] De que modos a filosofia e a literatura da diferença podem provocar a criação de procedimentos e estratégias específicas para outra relação com a escrita, a leitura e os modos de existência na escola? (SCHULER, 2014, p. 73).

Desse modo, entendemos que não se trata de fazer completamente outra coisa na escola do que vem sendo feito, até porque a escola ainda é um dos poucos lugares que ainda consegue fazer algum tipo de suspensão desse tempo produtivista se comparada aos demais espaços em que as crianças circulam, tais como como shoppings, programas de televisão, entre outros. 0 espaço da sala de aula, ainda pode ser tomado, mesmo com todos os atravessamentos de domesticação pelo qual a escola vem sendo produzida e foi gestada, como certa suspensão dos individualismos para pensar nos sintomas coletivos que nos atravessam. Mesmo com todos os investimentos que tentam tornar as escolas em espaços cada vez mais pasteurizados, podemos ainda tomar a aula como esse espaço público de estar com os outros, de pensar com os outros e 
não o mesmo que os outros, transformando pequenas questões em matéria de estudo, tal como o tempo.

Larrosa (2017, p. 129) nos lembra que skholé em grego significa que a escola estava vinculada ao tempo livre, a um "jogo desinteressado com o saber". Ter tempo para estudar, ler e escrever sem necessariamente "servir utilitariamente" à avaliação, ao Ideb, às medições de toda ordem. Por isso, a importância de tomar o tempo como matéria, como matéria para o pensamento na escola, com os outros, em aula, suspendendo essa infância acelerada, essa infância produtiva, essa infância idealizada, essa infância como falta, essa infância como promessa de futuro e trabalho. Criar o que ainda não existe, abrir um espaço no currículo, no próprio tempo escolar, para olhar o tempo de frente. Olhar o tempo com escola, com filosofia e com literatura. Prestar atenção no tempo. Ter tempo para encarar o tempo.

\section{DESDOBRAMENTO DO TEMPO: FILOSOFIA COM CRIANÇAS}

A partir da análise de tais práticas de escrita e leitura realizadas na escola, buscamos apontar alguns dos sintomas que apareceram com regularidade, os quais poderiam ser problematizados na oficina filosófica a ser proposta. Assim, a oficina foi realizada na escola com os alunos e alunas dos quais coletamos as escritas examinadas anteriormente e foi desenvolvida em dois dias com as duas turmas de 50 ano. A proposta foi desdobrar a preocupação com o tempo operada nas escritas analisadas, atravessando-a, pegando-a do avesso num exercício de pensamento, potencializando-a na criação de novas lidações com o tempo por meio de exercícios de escrita e leitura.

Desse modo, a oficina "Desdobramento do Tempo" traz como temática central pensar sobre nossa relação com o tempo, marcada principalmente pela preocupação com sua passagem rápida operada nas escritas examinadas. O problema pautado foi de que formas essa preocupação com o tempo produz modos de vida. Por isso, apostou-se em exercícios de desconstrução: apresentamos a temática da oficina filosófica e contextualização do surgimento dessa proposta de Desdobramento do Tempo. Lemos coletivamente o poema "A curta vida de nossos antepassados", de Wislawa Szymborska ${ }^{2}$, seguida de provocações tais como: por que nos preocupamos com o tempo? Como nos preocupamos com o tempo? Quando nos preocupamos com o tempo? Que preocupação é essa? Ela sempre existiu dessa forma? Estabeleceu-se uma conversação a partir dessas questões e de outras que os alunos e alunas foram produzindo. Trabalhamos também uma caixa com fragmentos filosóficos e literários sobre o tempo, em que cada aluno retirava um trecho para disparar a conversação no grupo, além de se contextualizar os autores em questão (a turma recebeu resumos) e como nos provocam a pensar diferente essa questão.

Juntamente a isso, apresentou-se as classificações sobre a duração, de Bergson (TREVISAN, 1995) ${ }^{3}$, e conversação sobre em que momentos da vida dos alunos esses diferentes modos de

\footnotetext{
2 SZYMBORSKA, W. Poemas. Tradução de Regina Przybycien. São Paulo: Companhia das letras, 2014.

3 Bergson classifica duração em: homogênea (que significa coisas de igual natureza e/ou outras semelhanças) e heterogênea (que significa coisas de natureza desigual e/ou outras diferenças) (TREVISAN, 1995).
} 
pensar o tempo podem ser pensados. Trabalhamos, igualmente, com trechos do texto Água Viva de Lispector, em que a autora fala sobre o que seria um "instante-semente". Após esses procedimentos, os alunos e alunas foram provocados a produzir um texto misturando e compondo o fragmento retirado da caixa com algum instante-semente de sua vida, trazendo aspectos de como se passou esse instante, a partir das conversações da oficina. Os alunos leram no coletivo suas produções, submetendo seu texto às perguntas e contribuições dos colegas. A partir de tais procedimentos, uma das turmas realizou uma pequena pesquisa; em que cada um escolheu uma pessoa para fazer as seguintes perguntas, registrando as respostas: o que é o tempo? Como é o tempo em que a gente vive? Já a outra turma buscou produzir fotografias de instante-semente (discutindo a dificuldade e o paradoxo de justamente fotografar o que escapa). Ambas as propostas foram retomadas e relacionadas com as produções já em andamento.

Quanto à turma que realizou as entrevistas e que buscou identificar os sintomas do nosso tempo presente, focou em problematizar o tempo de infância. Portanto, os problemas que pautaram esse encontro partiram dessas questões. Já a turma que trabalhou com as fotografias buscou pensar sobre a potência do instante. Por isso, a proposta desse momento consistiu em problematizar como nossa concepção utilitária do tempo atravessa a sociedade contemporânea e também problematizar as diferentes infâncias vividas no mundo, desconstruindo a ideia da infância idealizada como "tempo mágico", "tempo feliz".

O grupo trouxe as respostas e as fotografias produzidas para retomarem a problematização já iniciada, buscando identificar regularidades nessa lidação com o tempo no presente. Foi realizada uma conversação sobre as relações contemporâneas com o tempo e seus sintomas, a partir dos conceitos de tempo Cronos e Aion operados por Bergson (TREVISAN, 1995). Juntamente a isso, foi produzida uma problematização do tempo de infância por meio de fotografias e imagens artísticas, literárias e midiáticas. No momento em que as imagens eram manuseadas pelos alunos e alunas, dialogávamos sobre o conceito de infância, os discursos de infância e os tempos das infâncias. Que tempo é este? Podemos falar em infância em geral? Podemos falar em tempo no geral? Juntamente a isso, foram sendo atravessados textos teóricos, contos (tais como "Restos de carnaval" de Lispector ${ }^{5}$ ) e conversação sobre o que podemos pensar a partir desse conto, relacionando-o com o "tempo de infância" e com o "instante-semente".

A partir disso, os alunos e alunas produziram aforismos a partir dos estudos, conversas e problematizações da oficina, dos fragmentos da caixa sobre o tempo, das produções das entrevistas e fotografias, do conceito de duração homogênea (extensiva) e heterogênea (intensiva) de um momento, do tempo Cronos e Aion, do tempo de infância e da problematização dessa infância idealizada discutida em diferentes artefatos. Essas escritas foram lidas para o grupo, atravessadas de questões desse coletivo. Tal material constituiu a Exposição "Amarrar o tempo no poste", inspirados em um poema de Manoel de Barros ${ }^{6}$.

\footnotetext{
${ }^{4}$ Lispector, C. Água Viva. Rio de Janeiro: Rocco Editora, 1998.

${ }^{5}$ Lispector, C.Aprendendo a viver. Rio de Janeiro: Rocco Editora, 2004.
}

6 Barros, M. O tempo só anda de ida. Entrevista a Bosco Martins, 2007. Disponível em: <http://didilleite.blogspot.com.br/2015/08/poesia-alheia-do-tempo-manoel-de-barros.html> Acesso em: 10 out. 2016. 


\subsection{Outras forças que operaram na experiência do vivido}

A oficina filosófica "Desdobramento do tempo" teve como objetivo propor discussões sobre o tempo, dando-Ihes diferentes enfoques, problematizando conceitos dados a priori ou a reprodução de pensamento, realizando exercícios de lidação com a linha teórica da diferença e, por fim, produzir escritas em que fossem capazes de operar forças diferentes que as habituais na escola. Uma oficina que buscou a problematização das verdades vigentes e dos modos de existência dados como naturais atravessados pela questão do tempo e da infância.

Analisando as escritas produzidas durante a oficina com base nas discussões e nas escritas desses mesmos alunos coletadas e analisadas anteriormente, constatamos certas regularidades de forças reativas sendo operadas, mas também deslocamentos para o exercício de forças mais ativas. Não se trata de uma postura romântica ou de uma totalidade, mas de brechas que foram sendo construídas; possibilidades microfísicas de uma outra relação com o pensamento.

Sobre a divisão temporal da vida, após pensarmos e problematizarmos os diferentes modos de se ver, pensar e se relacionar com o tempo, as escritas ainda trazem uma classificação das etapas da vida, conforme as atividades habituais (do senso comum) de cada uma. São elas, com as respectivas explicações dos alunos durante a oficina: infância, "que é quando se brinca e se vai para a escola"; adolescência, "que é quando se estuda"; semi-adultez, "que é quando se estuda e se trabalha"; adultez, "que é quando se trabalha muito" e a velhice, "que é quando não se faz mais nada".

Inspirados por um excerto literário da caixa do tempo em que o autor fala que os velhos têm os bolsos cheios de tempo, os alunos passaram a pensar sobre esses clichês. Pensar na imagem de ter o bolso cheio de tempo fez submeter à crítica um modo de vida dado a priori. As escritas trouxeram isso, pois expressam a lógica mercadológica do tempo utilitário, sendo uma força enraizada que opera já nos modos de ser criança (cujo tempo é curto em função das diversas atividades que realizam). O pensamento operado nessas escritas é o de que a "falta de tempo" é sinônimo de compromisso, agenda cheia e/ou produção, portanto, sinônimo de sucesso.

Algumas escritas ainda operaram com a ideia moralizante de que aproveitar o tempo, a vida de modo geral é fazer muitas coisas da ordem produtiva, é realizar muitas atividades, é se envolver com diversas coisas ao mesmo tempo. Dessa forma, uma força moral ainda opera nessas escritas na forma de olhar para a velhice - como se fosse um tempo inútil. Supostamente as pessoas mais velhas já aproveitaram a vida, logo, não fazem mais nada. Porém, Sêneca (1993, p. 35) já dizia que "[...] não há por que pensar que alguém tenha vivido muito, por causa de suas rugas ou cabelos brancos". E essas questões foram problematizadas na oficina, quando, a partir de Sêneca, se problematizou uma vida curta ou longa não pelo tempo cronológico vivido, mas de como essa vida foi vivida em termos de tempo intensivo.

Trazendo novamente o conceito de infância, cuja força maior é o pensamento de que a criança ainda não é, sendo preparada para ser adulta, podemos problematizar o que as escritas trazem sobre a velhice: quando não se é mais adulto não se é mais (pois quando falta o tempo da utilidade econômica, não se faz mais nada). Inspirado em Deleuze, López (2008, p. 10) diz que “o 
único tempo dos corpos e dos estados de coisas é o presente", problematizando o pensamento colocado em funcionamento nessas escritas. A velhice pode ser tempo da possibilidade, do presente, de escolher a intensidade com que se vive esse tempo. Por isso a potência, por exemplo, dos textos de Sêneca e Lispector para valorar de outro modo o instante. López (2008, p. 29), a partir de Deleuze, irá dizer que o acontecimento não existe no tempo cronológico, mas em um tempo intensivo, acrescentando que:

[...] o instante é a porta de algo mais profundo que o tempo. Porque o que chamamos de tempo é somente o que a consciência consegue representar: um passado, um presente e um futuro que se sucedem em uma linha. Uma linha estática que desenhamos em nossa imaginação. Mas o instante se furta ao tempo assim representado [...].

Assim, durante a oficina umdos fragmentos da caixa perguntava ao leitor se ele já tinha pensado sobre o início do tempo.Essa discussão que busca deslocar o tempo obrado unicamente na ordem cronológica pôde ser trabalhada a partir da escrita aforística produzida por uma das crianças na oficina: "antes do tempo, todos prestavam atenção no tempo". Essa escrita muitos nos fez pensar sobre certa relação contabilística com o tempo e a possibilidade de certa suspensão. Ela faz alargar uma potência de pensamento singular, porque problematizou a possibilidade de uma relação mais intensiva com o tempo, inspirada em Sêneca (1993) e suas discussões. Como era nossa relação com o tempo antes de ser dividido, medido, calculado, valorado por produção como o funcionamento contemporâneo? Como Foucault nos faz pensar, a partir de Sêneca, sobre a relação com o tempo quando diz que é a única coisa pela qual devemos lutar e ser avarentos, no sentido de construir nossa vida como uma obra de arte? O que significa, na perspectiva do cuidado de si foucaultiana, desperdiçar tempo? Desse modo, quando instigadas a escreve sobre o tempo após as discussões da oficina, muitos alunos e alunas escreveram sobre instantes-semente, momentos singulares em que a preocupação com a utilidade do tempo se distancia minimamente.

Outra questão surgida nesse espaço foi o espanto dos alunos sobre a impossibilidade da captura do instante, o quanto não é habitável enquanto um território (LÓPEZ, 2008). A partir disso, trouxeram recorrentemente como o tempo passa rápido quando estão alegres. Deleuze citado por López (2008, p. 10) afirma que "o tempo dos acontecimentos é o devir", tempo esse que atravessou algumas escritas. A passagem do tempo que antes preocupava agora se mostra com menos força. A intensidade dos momentos enfatiza que o aproveitamento do tempo não se dá na quantidade de tarefas que realizamos, mas na sua potência de afirmação da vida (os alunos pontuaram, por exemplo, com quem compartilham esse tempo). Escritas que deslocaram, em brechas, a importância do que se faz com o tempo que se vive em detrimento de quanto tempo se tem cronologicamente, uma vez que apontam que a preocupação exagerada com o passado e futuro nos tira do presente.

Esses deslocamentos no modo de pensar o tempo - cronológico e intensivo - e de se relacionar com ambos, concretizados pelas escritas podem remeter ao que Aquino (2011), baseado em Foucault, afirma: de que o processo de escrever pode consistir numa experiência de transformação daquilo que se pensa e do que se é, mesmo que se tratando de brechas microfísicas (e esta é a potência). 
Outros sintomas também vão sendo operados nas escritas, como a diminuição da força pastoral, bem como deslocamentos de uma infância infantilizada a partir das discussões realizadas. No exame das escritas coletadas anteriormente à oficina, o discurso salvacionista e pastoral cristão era muito evidente, em que os materiais traziam ações morais voltadas ao outro, a culpabilidade pelos problemas ambientais e afirmavam que com o perdão de Deus conseguiríamos salvar o mundo e as pessoas.

Tendo como referência outra literatura que não a chamada por Larrosa (2004) de burocrata do pensamento, também outras são as forças que foram colocadas em funcionamento durante a oficina filosófica, tanto pela escolha dos materiais como pelos exercícios que os próprios alunos se propuseram no decorrer das discussões. Esse movimento traz o quanto os procedimentos operados produzem outras forças, outras linhas de pensamento. Enfatiza-se, assim, que a forma arrasta o conteúdo (DELEUZE; GUATTARI, 2003), pois pode produzir outros sentidos. Nesse caso, pensando todo o contexto da oficina (temática, materiais, metodologia), foi possível experimentar uma outra relação com o pensamento, fazendo escapes ao pensamento dogmático, mesmo que em brechas, de modo muito pontual. O exercício de pensamento realizado a partir das escritas escapou temporariamente, em alguns momentos, a uma lógica que Foucault (2004) chama de registro confessional. Um dos pontos importantes foi o deslocamento de uma infância sempre ligada às ideias de felicidade, alegria, prazer para as discussões sobre a morte, a finitude da vida que atravessaram as escritas das crianças, quando da problematização do tempo.

Assim, podemos pensar o tempo de infância não como idade cronológica, mas como uma postura frente à vida, como o poeta Manoel de Barros que diz só ter tido infância, através do olhar curioso e aberto ao mundo. O exercício de pensar sobre o tempo de vida foi atravessado muito fortemente pela discussão sobre a morte, tema quase inexistente na escola na contemporaneidade. Portanto, essas escritas além de provocarem uma possibilidade de experimentar um pensamento não tão dogmático sobre o tempo, operam com a infância não como tempo utópico, nem tempo cronológico. As escritas mostraram uma infância crua, vivida no cotidiano e pouco romântica, carregadas pelo devir das experiências vividas, atravessadas por instantes que marcaram as existências. Forças que normalmente são silenciadas dentro do currículo escolar.

E foi interessante notar que enquanto que uma turma ocupava-se em falar sobre guerra e suas marcas nas infâncias (muito tocados pelo drama dos refugiados no presente), a outra turma se deteve em relatar experiências pessoais com o término do tempo de vida de seus avós. Ou seja, enquanto uma turma fazia o exercício de pensar sobre as infâncias do mundo, a outra turma fazia o exercício de atravessar as marcas de suas próprias infâncias. Segundo López (2008, p. 55), "só pensamos quando somos provocados desde fora de nosso poder, de nosso saber, de nossa identidade pessoal". E ainda acrescenta "o sentido e o valor de um pensamento dependem da relação que esse pensamento estabelece com as forças múltiplas e heterogêneas que se apoderam das coisas" (LÓPEZ, 2008, p. 72).

Dessa forma, as forças que operavam as escritas dos alunos foram modificadas pela relação diferencial que estabelecemos durante as leituras, escritas e conversações na oficina, produzindo novos modos de pensar, mesmo que em brechas, de modo microfísico. Portanto, o trabalho de filosofia com crianças, operado não como uma disciplina escolar, mas como certa relação com o 
pensamento e com a vida, pode ter uma potência de carregar forças de exercícios de pensamento, para além dos clichês que entopem os currículos escolares.

\section{AINDA ALGUMAS CONSIDERAÇÕES}

Frente ao exposto, retomamos a ideia de que não foi através da oficina filosófica que os alunos pensaram, pois eles o faziam antes (e sempre), mas que o modo de pensar é que sofreu deslocamentos durante a prática de filosofia. Isso não significa que uma escrita seja melhor do que a outra, mas que operam forças diferentes. Então, o pensar, que é produzido pela provocação do fora, pelo encontro, viabilizado por diferentes intercessores (nesse caso as imagens, os colegas, os textos, as escritas, as fotografias, as entrevistas, as conversações, a professora) desempenharam papel de noturnar as concepções previamente claras dos alunos, como transcrito por Manoel de Barros (2009).

Tratou-se de apostar em uma prática filosófica que tem implicações éticas e políticas importantes, quando nos debruçamos a pensar sobre nossas vidas e nossas relações com o tempo, o instante, a morte, os utilitarismos de toda ordem, a produtividade. Tratou-se de uma prática de tomar-se a si mesmo, de ocupar-se de si em relação àquilo que parece mais naturalizado para tentarmos pensar de outros modos. Por isso, práticas de deformação e de formação. Tratou-se de oferecer signos a serem pensados nesse coletivo que pode se constituir uma sala de aula. Tratouse de estar junto de outras formas.

Ressaltamos que a referência é essa prática específica de filosofia, pois há diferentes modos de se operar com a ela. Optamos por vivê-la como exercício do pensamento sobre o próprio pensamento, problematizando minimamente nossas verdades e modos de existência. Nessa perspectiva conceitual foram desenvolvidos os movimentos da pesquisa, cujo principal objetivo era a busca pela abertura de possibilidades para agir com a potência de pensamento, com a filosofia com crianças, fundamentalmente dentro da escola. Não como didática totalizadora, não como aplicação dos conceitos aqui discutidos, não como novo receituário e igreja a ser seguida, mas como brechas que forçam a descolonização do pensamento, a abertura de outras possibilidades na lidação com o saber, a partir de práticas de leitura e escrita capazes de intervir minimamente no exercício de pensamento e de vida. E de um pensamento e de uma vida mais afirmativos!

\section{REFERÊNCIAS}

AQUINO, J. G. (2011). A escrita como modo de vida: conexões e desdobramentos educacionais. Educação e Pesquisa, 37(3), 641-656.

ÀRIES, P. (1981). História Social da Criança e da Família. 2ª Ed. Rio de Janeiro: LTC.

BARROS, M. (2007).O tempo sóanda de ida. [Entrevistaa Bosco Martins]. Disponívelem: <http://didilleite.blogspot.com.br/2015/08/poesia-alheia-do-tempo-manoel-debarros.html> Acesso em: 10 out. 2016.

BARROS, M. de (2009). O fazedor de amanhecer. São Paulo: Richmod Educação. 
DELEUZE, G. \&GUATTARI, F. (2003).Kafka: para uma literatura menor. [Tradução de Rafael Godinho]. Lisboa: Assírio \& Alvim.

FOUCAULT, M. (2004). A escrita de si. In: MOTTA, Manoel Barros da. Ética, sexualidade, política.[Tradução Elisa Monteiro, Inês Autran Dourado Barbosa]. Rio de Janeiro, RJ: Forense Universitária.

FOUCAULT, M. (2005). O que é um filósofo? In: MOTTA, Manoel Barros da. Arqueologia das ciências e história dos sistemas de pensamento.[Tradução de Elisa Monteiro]. 2a Ed. Rio de Janeiro, RJ: Forense Universitária.

FOUCAULT, M. (2007). História da sexualidade 2: o uso dos prazeres. 12a Ed. [Tradução de Maria Thereza da Costa Albuquerque; Revisão técnica de José Augusto Guilhon Albuquerque]. Rio de Janeiro: Edições Graal.

FOUCAULT, M. (2011). A Hermenêutica do Sujeito: curso dado no Collège de France (1981-1982). [Edição de F. Ewald, A. Fontana, F. Gros]. [Tradução de Marcio A. da Fonseca, Salma T. Muchail]. 3a Ed. São Paulo: Martins Fontes.

GALLO, S. D. \& VEIGA-NETO, A. (2007). Ensaio para uma Filosofia da Educação. Educação, 3 (Edição Especial Foucault pensa a Educação), 16-25.

KOHAN, W. O. (1998). Fundamentos para compreender e pensar a tentativa de M. Lipman. In: W.O. KOHAN\&A.M. WUENSCH (Orgs.). Filosofia para crianças: a tentativa pioneira de Matthew Lipman. Petrópolis, RJ: Vozes.

KOHAN, W. O. \& WUENSCH, A. M. (Org.) (1998). Filosofia para crianças: a tentativa pioneira de Matthew Lipman. Petrópolis, RJ: Vozes.

KOHAN, W. O. (1999). Filosofia e infância: pontos de encontro. In: W.O. KOHAN\&D. KENNEDY (Orgs.) Filosofia e infância, possibilidades de um encontro. Petrópolis, RJ: Vozes.

KOHAN, W. O. (2003).Infância. Entre educação e filosofia. Belo Horizonte, MG: Autêntica.

KOHAN, W. O. (2009).Filosofia: o paradoxo de aprender e ensinar. Belo Horizonte, MG: Autêntica.

KOHAN, W. O. (2012). Palavras, passos e nomes para um projeto. In: W.O. KOHAN\&B.F. OLARIETA (Orgs.) A escola pública aposta no pensamento. Belo Horizonte: Autêntica Editora.

LARROSA, J. (2004). A operação ensaio sobre o ensaiar e o ensaiar-se no pensamento, na escrita e na vida. Educação \& Realidade, 29(1), 27-43.

LARROSA, J.; VENCESLAO, M. (2017). Um povo capaz de skholé. Elogio das Missões Pedagógicas da II República Espanhola. In: LARROSA, J. (Org.). Elogio da escola. [Tradução de Fernando Coelho]. Belo Horizonte: Autêntica. (Coleção Educação: Experiência e Sentido).

LISPECTOR, C. (1998). Água Viva. Rio de Janeiro: Rocco Editora.

LISPECTOR, C. (2004). Aprendendo a viver. Rio de Janeiro: Rocco Editora.

LÓPEZ, M. V. (2008). Acontecimento e experiência no trabalho filosófico com crianças. Belo Horizonte: Autêntica Editora. 
MATOS, S. R. L. (2009). Achadouro infantil. Anais de artigo completo do 15o Encontro Sul-RioGrandense de Pesquisadores em História da Educação Infâncias, Cultura Escrita e História da Educação. Caxias do Sul, RS: Programa de Pós-Graduação em Educação da Universidade de Caxias do Sul.

OLEGÁRIO, F.\& MUNHOZ, A. V. (2014). Escrita ensaística: fragmentos menores. Fractal,Rev. Psicol., 26(1), 155-164.

RESENDE, H. (2015). A infância sob o olhar da Pedagogia: traços da escolarização na Modernidade. In: H. RESENDE (Org.). Michel Foucault: o governo da infância. Belo Horizonte, MG: Autêntica.

SCHULER, B. (2014). Por entre escritas, leituras e cadeiras: o procedimento genealógico e o cuidado de si. In: B. SCHULER, B.;R.L. MATOS; S.M. CORAZZA (Orgs.) Caderno de notas 6: experimentações de escrita, leitura e imagem na escola. Porto Alegre, RS: UFRGS, DOISA.

SÊNECA, A. (1993). Sobre a brevidade da vida. [Tradução de William Li]. São Paulo: Nova Alexandria.

SZYMBORSKA, W. (2014). Poemas.[Tradução de Regina Przybycien]. São Paulo: Companhia das Letras.

TREVISAN, R. M. (1995). Bergson e a Educação. Piracicaba: Editora Unimep.

VEIGA-NETO, A. (2016). Espaços, Tempos e Disciplinas: as crianças ainda devem ir à escola? Anais doSimpósio Espaços e tempos escolares do 10 ENDIPE, Rio de Janeiro. Disponível em: <http://www.lite.fe.unicamp.br/cursos/nt/ta5.4.htm> Acesso em: 08 set. 2016. 